\title{
Co-administration of sodium arsenite and ethanol: Protection by aqueous extract of Aframomum longiscapum seeds
}

\author{
Solomon E. Owumi, Oyeronke A. Odunola, Mohammed Aliyu \\ Department of Biochemistry, Molecular Biology and Cancer Research Laboratories, University of Ibadan, Ibadan, Nigeria \\ Submitted: 24-08-2011 \\ Revised: 12-10-2011 \\ Published: 27-07-2012
}

A B STRACT

Background: Human exposure to arsenicals, its toxicity, subsequent adverse effects on health has been widely reported and implicated in the etiology of several cancers. Objectives: We investigated the effect of Aframomum longiscapum (AL) extracts on sodium arsenite (SA) and ethanol (EtOH)induced toxicities in rats. Materials and Methods: Male rats were fed SA, EtOH, and SA + EtOH, with or without AL for 5 weeks. Hepatic transaminases were assessed in serum, micronucleated polychromatic erythrocytes (mPCEs) from bone marrow, liver histopathology, and semen quality from caudal epididymis were assessed, respectively, and data were represented as mean $\pm S D$, analyzed by ANOVA. Results: SA, SA $+\mathrm{EtOH}$, and $A L$ alone induced mPCEs formation in rat bone marrow $(P<0.05)$. A decrease $(P<0.05)$ in mPCEs in $A L+\mathrm{SA}+$ EtOH-treated rats compared with $\mathrm{SA}$, and $\mathrm{SA}+\mathrm{EtOH}$ was observed. SA and $\mathrm{EtOH}$ treatment increased serum hepatic transaminases $(P<0.05)$ relative to control, while $A L$ treatment resulted in a decrease $(P<0.05) . A L, \mathrm{SA}$, and $\mathrm{SA}+\mathrm{EtOH}$ treatment decreased sperm count and motility $(P<0.05)$ with no effect on viability compared with control. Semen morphological abnormalities showed no difference $(P>0.05)$ across the treated groups. Hepatic histopathology indicated mild mononuclear cellular infiltration in the control group. Necrotic hepatocyte were observed in SA, SA $+\mathrm{EtOH}$ treated groups, with no visible lesions seen in the $A L$ treated group. Mild hepatocyte congestion of the portal vessels was observed in $A L+\mathrm{SA}+\mathrm{EtOH}$-treated groups. Conclusion: The $A L$ extract exhibited anticlastogenic and hepatoprotective potentials, reduced sperm count, motility, with no effect on viability and morphology. Our findings suggest that $A L$ may mitigate the effect of arsenicals-induced clastogenicity implicated in chemical carcinogenesis.

Key words: Aframomum longiscapum, arsenite, ethanol, micronuclei

\section{INTRODUCTION}

Inorganic arsenic compounds are widely distributed in nature and epidemiological evidence exit associating occupational and environmental exposure to arsenic with human carcinogenesis. ${ }^{[1]}$ For instance, exposure to trivalent and pentavalent forms of arsenic causes characteristic skin alterations (ulceration), including hyperkeratosis and skin cancer. ${ }^{[2]}$ Studies conducted in Taiwan ${ }^{[3]}$ Chile, ${ }^{[4]}$ and $\operatorname{Japan}^{[5]}$ indicated a connection between arsenic exposure from contaminated drinking water and cancer development among inhabitants. It is also known that arsenic interacts

Address for correspondence:

Dr. Solomon E. Owumi, Department of Biochemistry, Molecular Biology and Cancer Research Laboratories, University of Ibadan, Ibadan, Oyo State - 200005, Nigeria. E-mail: zicri@hotmail.com with a wide variety of other substances, metals inclusive potentiating its effects or vice versa. ${ }^{[6]}$ There is growing evidences that sodium arsenite (SA) intoxication can compromise the integrity of the liver in laboratory animals and maybe humans. ${ }^{[7-10]} \mathrm{A}$ more recent study suggests the use of antioxidants from medicinal plants and antioxidantrich foods for the management of arsenicosis ${ }^{[1]]}$ and in hepatoprotection. ${ }^{[12]}$

Carcinogenesis is frequently associated with DNA damage, changes in ploidy of cells, and nonrandom chromosome aberrations all of which can result from exposure to arsenicals. ${ }^{[11]}$ Association between chronic alcohol abuse, cirrhosis, and the development of hepatocellular carcinoma (HCC) is well documented. ${ }^{[13,14]}$ The use of arsenic contaminated water for brewing ethanol (EtOH) locally cannot be ruled out in community where arsenic contamination is endemic. Acute and chronic EtOH 
treatment has also been shown to increase the production of reactive oxygen species, lower cellular antioxidant levels, and enhance oxidative stress in many tissues, especially the liver. ${ }^{[15]} \mathrm{EtOH}$-induced oxidative stress is one of the major mechanism through which EtOH induces liver injury. ${ }^{[15]}$

Aframomum species are commonly consumed in some other countries of the world as a spice, which also finds application as a notable medicinal plant in Nigeria herbal remedies. Studies carried out on other Aframomum species, e.g. Aframomum melegueta, ${ }^{[16]}$ and Aframomum danielli ${ }^{[17]}$ has been reported to have high antioxidant potentials. However, there is dearth of information on Aframomum longiscapum (AL) Schumann (Zingiberaceae) especially its phytochemical profile which may be hepatoprotective to an extent or toxic on the other hand. This study was therefore undertaken to evaluate the effect of aqueous extract of $A L$ seeds on $\mathrm{SA}$ and $\mathrm{EtOH}$-induced toxicities in male Wister albino rats.

\section{MATERIALS AND METHODS}

\section{Chemicals}

Sodium arsenite (BDH Chemicals Ltd., Poole, England) $2.5 \mathrm{mg} / \mathrm{kg}$ body weight (corresponding to one-tenth of the oral LD of SA) was administered to a rat. ${ }^{[18]} \mathrm{EtOH}$ was dissolved in distilled water to prepared 3\% EtOH (v/v) and $0.3 \mathrm{~mL}$ was administered to a rat. All other reagents and chemicals were of analytical grade.

\section{Plant materials}

The $A L$ seeds were sourced locally from the market in Ibadan, Nigeria, and a specimen was identified at the Herbarium in Botany Department, University of Ibadan. The $A L$ seeds were pulverised, $650 \mathrm{~g}$ was measured out and macerated in $1300 \mathrm{~mL}$ of distilled water for $72 \mathrm{~h}$. The aqueous extract was concentrated in a rotary evaporator, lyophilized and thereafter preserved in a refrigerator at $4^{\circ} \mathrm{C}$ for further use.

\section{Phytochemical screening}

A small portion of the dry extract was subjected to the phytochemical test using the method of Trease ${ }^{[19]}$ to test for flavonoids, alkaloids, tannins, anthraquinones, saponins, and cardenolides.

\section{Experimental animals}

Forty 12-week's old Male Wister's albino rats weighing between 200 and $250 \mathrm{~g}$ were purchased from Covenant Farm, Ibadan, Nigeria, and housed in the Primate Colony Department of Biochemistry, University of Ibadan. They were fed with rat pellets containing carbohydrate, at least $20 \%$ protein, $3.5 \%$ fat, $9.0 \%$ fiber, $1.2 \%$ calcium, $0.7 \%$ phosphorus, vitamin; mineral per mix purchased from
Livestock Feeds Ibadan, Nigeria, and water ad libitum.

\section{Experimental protocols}

Animals were distributed randomly into eight groups of five rats each. Group I served as control. Those in group II were given $2.5 \mathrm{mg} / \mathrm{kg}$ body weight of SA alone via oral intubation, groups III and IV were administered EtOH (3\%w/v) AL (122.5 mg/kg body weight) ${ }^{[16]}$ respectively. While group $\mathrm{V}$ was given $\mathrm{SA}+\mathrm{EtOH}$, group VI AL + EtOH and group VII SA + AL. Group VIII were administered $\mathrm{SA}+A L+\mathrm{EtOH}$. Aqueous extracts of $A L$ were administered every third day. Animals in groups VI, VII, and VIII were primed with $A L$ and simultaneously fed with $\mathrm{SA}$ and $\mathrm{EtOH}$ as required. All the rats had free access to rat pellets and distilled water ad libitum throughout the period of the study.

Twenty-four hours after the last treatment, the rats was killed by cervical dislocation and whole blood collected. Clastogenic effects were evaluated in the rat bone marrow using the micronucleus assay as previously described. ${ }^{[20]}$ Two hours prior to be killed, the animals were injected (i.p.) with $0.04 \%$ colchicines $(1 \mathrm{~mL} / 100 \mathrm{~g}$ body weight). Bone marrow cells from both femurs were used for preparing slides. The slides were fixed, air-dried, and pre-treated with May-Grunewald solution and subsequently stained with Giemsa solution. The slides were scored for the presence of micronucleated polychromatic erythrocytes (mPCEs) according to a standard procedure by using a light microscope and a tally counter.

Hepatic $\gamma$-glutamyl transferase $(\gamma-G T)$ activities were determined in serum using the method of Sazsz, and Gesellschaft fur Klinische Chemie, respectively, as described. ${ }^{[21]}$ The activities of alanine amino transferase (ALT) and aspartate amino transferase (AST) were also evaluated based on the method of Reitzman and Frankel as described. ${ }^{[22]}$ Limited histopathological and sperm quality examinations of the liver and caudal epididymis of the testis, respectively, were performed at the Veterinary Pathology Department, University of Ibadan, Nigeria.

\section{Statistical analysis}

The data were expressed as mean \pm standard deviation. Differences between the groups were analyzed by one-way analysis of variance (ANOVA) with the aid of Statistical Package for Social Sciences (SPSS) software, SPSS Inc., Chicago, Standard version 10.0.1. $P<0.05$ were considered statistically significant for differences in mean.

\section{RESULTS}

Phytochemical analysis of aqueous extract of $A L$ seed indicated the presence of alkaloids, cardenolides, saponins, 
and flavonoids and the absence of anthraquinones and tannin [Table 1]. There was an increase in final body weight of mice in groups I-VII with group IV showing the highest gain in final body weight [Table 2], an insignificant $(P<0.05)$ reduction in final body weight of group VIII animals were also observed. Compared to control, liver and relative liver weight in all groups except the EtOHtreated group reduced across board [Table 2] significantly $(P<0.05)$. Table 3 shows induction of mPCEs in rat bone marrow cells after exposure to $\mathrm{SA}, \mathrm{EtOH}$ and $A L$ alone and when co-administered. The mPCEs formed by the $\mathrm{SA}, \mathrm{EtOH}+\mathrm{SA}$ treated group were significant and occur at almost the same frequency. AL appears to induce micronuclei formation with a 2.5 -fold increase when administered alone and appears to mitigate SA and EtOH-induced mPCE formation decreasing it by almost $50 \%$ when compared to control. Table 4 shows the serum level of hepatic transaminases ( $\gamma$-GT, AST and ALT) in sera of treated rats. SA and $\mathrm{EtOH}$ co-administration increase the serum level of AST when compared to control significantly $(P<0.05)$ over three-fold. The $\gamma$-GT level was increased two-fold over control but was within a normal range. SA and $A L$ single treatment alone also increased the serum level of these transaminases [Table 4]. However, $A L$ when administered with $\mathrm{SA}$ in combination with EtOH drastically reduced the level of hepatic transaminases in serum. Sperm count, motility, and viability were affected by SA treatment, co-treatment with $\mathrm{SA}, \mathrm{EtOH}$ and $A L$ resulted in a reduction in sperm counts and motility and viability [Table 5]. Overall sperm morphology was affected with an increase percentage of abnormal sperm cells

\begin{tabular}{lc}
\multicolumn{2}{l}{ Table 1: Phytochemical profile of aqueous } \\
extract of Aframomum longiscapum seeds \\
\hline Components & Results \\
\hline Alkaloids & Present \\
Cardenolides & Present \\
Anthraquinones & Absent \\
Saponins & Present \\
Tannins & Absent \\
Flavonoids & Present \\
\hline
\end{tabular}

across treatment groups compared to control [Table 5]. A $25 \%$ increase in total sperm abnormalities was observed in the groups treated with $\mathrm{SA}$ or $\mathrm{EtOH}$ only. $A L$ alone tend to induce a $62 \%$ increase in sperm morphological abnormalities and in groups where it is co-administered with SA and EtOH, which singly exhibited a 50\% percentage morphological abnormality relatively lesser than when in the absence of $A L$. Limited histopathology of the liver showed diffuse periportal vacuolar degeneration of hepatocytes with very mild cellular infiltration by mononuclear cells in control rats. In the SA-treated rat there are multiple areas of extensive vacuolar degeneration of hepatocytes. The severity in hepatic degeneration and diffused necrosis cells were more pronounced in the SA and $\mathrm{EtOH}$-treated group. In the aqueous extract of $\mathrm{AL}$ seed treated rats, little or no visible lesions were observed, but there were mild hepatic degeneration, congestion of the portal vessels and mononuclear cellular infiltration in the $\mathrm{SA}, \mathrm{EtOH}$ and aqueous extract of $\mathrm{AL}$ seed treated rats. EtOH alone treatment exhibited diffuse periportal vacuoles of hepatocytes with mild cellular infiltration by mononuclear cells.

\section{DISCUSSION}

Exposure to arsenite has been linked to diverse effects in both experimental animals and humans. ${ }^{[23-27]}$ As the site of xenobiotics metabolism the liver is an important target organ for arsenic toxicity ${ }^{[28]}$ upon assimilation. Arsenic has been claimed to be of clinical utility in the treatment of syphilis, amoebiosis, and certain other diseases ${ }^{[25]}$ and also has been used in Fowler solution in the treatment of arthritis; ${ }^{[25]}$ however, arsenic intoxication in experimental animals has been associated with hepatic tumors, ${ }^{[26]}$ the inhibition of testicular steroidogenic function, ${ }^{[29]}$ and spermatogenesis, ${ }^{[27]}$ as well as with severe metabolic disorders such as diabetes in humans. ${ }^{[23,24]} \mathrm{It}$ is known that arsenic can act as co-mutagen due to its ability to inhibit the activities of thiol containing enzymes, ${ }^{[30]}$ such as DNA ligase $^{[31]}$ resulting in defective DNA replication, repair,

\begin{tabular}{lccccc}
\multicolumn{6}{l}{ Table 2: Body and organ weight of Albino Wistar rats treated with SA, EtOH, and AL } \\
\hline Group & IBW (g) & FBW (g) & \% WC & LW (g) & RLW (\%) \\
\hline Control (I) & $201 \pm 2.81$ & $210 \pm 4.50$ & 4.48 & $6.23 \pm 0.51^{\mathrm{b}}$ & $3.02 \pm 0.53^{\mathrm{b}, \mathrm{c}}$ \\
SA (II) & $205 \pm 3.18$ & $215 \pm 5.69$ & 4.88 & $5.09 \pm 0.31^{\mathrm{a}, \mathrm{b}, \mathrm{c}}$ & $2.38 \pm 0.21^{\mathrm{a}}$ \\
EtOH (III) & $205 \pm 5.13$ & $210 \pm 6.23$ & 2.43 & $7.22 \pm 1.05^{\mathrm{b}}$ & $3.44 \pm 0.89^{\mathrm{b}, \mathrm{c}}$ \\
AL (IV) & $185 \pm 4.69$ & $205 \pm 3.92$ & 10.81 & $4.19 \pm 0.65^{\mathrm{a}, \mathrm{b}, \mathrm{c}}$ & $2.04 \pm 0.16^{\mathrm{a}, \mathrm{c}}$ \\
SA + EtOH (V) & $235 \pm 3.69$ & $250 \pm 5.69$ & 6.38 & $6.44 \pm 0.65^{\mathrm{b}}$ & $2.47 \pm 0.15^{\mathrm{a}, \mathrm{b}}$ \\
AL + EtOH (VI) & $210 \pm 3.26$ & $215 \pm 4.01$ & 2.38 & $7.04 \pm 1.2$ & $3.27 \pm 0.75$ \\
SA + AL (VII) & $212 \pm 2.45$ & $220 \pm 3.21$ & 3.77 & $4.69 \pm 59$ & $2.13 \pm 0.4$ \\
SA + AL + EtOH (VIII) & $180 \pm 3.69$ & $175 \pm 5.20$ & -2.78 & $4.24 \pm 0.44^{\mathrm{a}, \mathrm{b}, \mathrm{c}}$ & $2.45 \pm 0.29^{\mathrm{a}}$ \\
\hline
\end{tabular}

Values are expressed as means $\pm \mathrm{SD}$, a Mean difference is significant $(P<0.05)$ when compared with group I, ${ }^{\mathrm{b}}$ Mean difference is significant $(P<0.05)$ when compared with group II, cMean difference is significant $(P<0.05)$ when compared with group III, IBW = Initial body weight, FBW = Final body weight, WC = Weight change, LW = Liver weight, $\mathrm{RLW}=$ Relative liver weight, $\mathrm{SA}=$ Sodium arsenite, $\mathrm{EtOH}=$ ethanol, $\mathrm{AL}=$ Aframomum longiscapum 


\begin{tabular}{lc} 
Table 3: Induction of micronucleated \\
polychromatic erythrocytes (mPCEs) in rat bone \\
marrow cells after exposure to sodium arsenite \\
\multicolumn{2}{l}{ and ethanol, Aframomum longiscapum } \\
\hline Group & Number of mPCEs/1000 PCEs \\
\hline Control (I) & $6.20 \pm 3.69$ \\
SA (II) & $26.50 \pm 2.12$ \\
EtOH (III) & $6.50 \pm 2.65$ \\
AL (IV) & $7.35 \pm 2.54$ \\
SA + EtOH (V) & $25.80 \pm 2.17$ \\
AL + EtOH (VI) & $6.68 \pm 2.17$ \\
SA + AL (VII) & $15.40 \pm 5.18$ \\
SA + AL + EtOH (VIII) & $13.60 \pm 4.22$ \\
\hline
\end{tabular}

Values are expressed as means $\pm \mathrm{SD}$, ${ }^{a}$ Mean difference is significant $(P<0.05)$ when compared with group I, bMean difference is significant $(P<0.05)$ when compared with group II, ' Mean difference is significant $(P<0.05)$ when compared with group III, $\mathrm{SA}=$ Sodium arsenite $, \mathrm{EtOH}=\mathrm{Ethanol}, \mathrm{AL}=$ Aframomum longiscapum

\begin{tabular}{|c|c|c|c|}
\hline Group & AST (U/I) & ALT (U/I) & V-GT (U/I) \\
\hline Control (I) & $47.5 \pm 9.19^{a, c}$ & $23.12 \pm 5.89^{c}$ & $2.55 \pm 1.90^{c}$ \\
\hline SA (II) & $66 \pm 10.56^{a, c}$ & $29.87 \pm 2.80$ & $4.63 \pm 1.64^{a}$ \\
\hline EtOH (III) & $83.34 \pm 10.45^{a, b, c}$ & $23.0 \pm 3.22^{\mathrm{a}, \mathrm{b}, \mathrm{c}}$ & $5.02 \pm 1.23^{a, b, c}$ \\
\hline $\mathrm{AL}(\mathrm{IV})$ & $52.71 \pm 8.67$ & $25.11 \pm 4.01$ & $3.21 \pm 2.0$ \\
\hline $\mathrm{SA}+\mathrm{EtOH}(\mathrm{V})$ & $138.60 \pm 10.04^{a, b}$ & $31.04 \pm 2.63^{a}$ & $5.33 \pm 2.54^{a}$ \\
\hline $\mathrm{AL}+\mathrm{EtOH}(\mathrm{VI})$ & $69.11 \pm 10.31$ & $27.64 \pm 3.21$ & $4.19 \pm 0.65$ \\
\hline$S A+A L(V I I)$ & $92.60 \pm 28.63^{\mathrm{b}, \mathrm{c}}$ & $19.84 \pm 3.09^{b, c}$ & $3.01 \pm 0.63$ \\
\hline $\begin{array}{l}\mathrm{SA}+\mathrm{AL}+ \\
\mathrm{EtOH}(\mathrm{VIII})\end{array}$ & $34.20 \pm 37.98^{\mathrm{b}, \mathrm{c}}$ & $21.92 \pm 3.97^{b, c}$ & $3.01 \pm 2.10^{\mathrm{b}, \mathrm{c}}$ \\
\hline
\end{tabular}

Values are expressed as means $\pm \mathrm{SD}$, a Mean difference is significant $(P<0.05)$ when compared with group I, bMean difference is significant $(P<0.05)$ when compared with group II, 'Mean difference is significant $(P<0.05)$ when compared with group III, $\mathrm{SA}=$ sodium arsenite; $\mathrm{EtOH}=$ Ethanol, $\mathrm{AL}=$ Aframomum longiscapum

\begin{tabular}{lcccc}
\multicolumn{4}{l}{ Table 5: Sperm quality in terms of count, motility, viability, and abnormalities in the treated rats } \\
\hline Group & Sperm counts & Sperm motility (\%) & Sperm viability (\%) & Total abnormalities (\%) \\
\hline Control (I) & $126.00 \pm 8.49$ & $90.00 \pm 3.00$ & $95.50 \pm 3.54$ & $8.76 \pm 1.12$ \\
SA (II) & $106.43 \pm 8.48$ & $70.20 \pm 3.10$ & $82.50 \pm 3.54$ & $10.07 \pm 1.86$ \\
EtOH (III) & $110.00 \pm 11.23$ & $80.63 \pm 2.69$ & $86.34 \pm 2.46$ & $10.00 \pm 1.43$ \\
AL (IV) & $85.50 \pm 10.85^{\mathrm{a}}$ & $52.50 \pm 2.89^{\mathrm{a}, \mathrm{b}}$ & $93.25 \pm 3.95$ & $13.36 \pm 2.38$ \\
SA + EtOH (IV) & $108.00 \pm 9.14$ & $70.70 \pm 3.20$ & $80.20 \pm 3.27$ & $12.99 \pm 1.76$ \\
AL + EtOH (VI) & $80.12 \pm 8.52$ & $50.27 \pm 1.94$ & $90.51 \pm 2.66$ & $13.85 \pm 2.04$ \\
SA + AL (VII) & $94.76 \pm 10.27$ & $55.20 \pm 3.16$ & $86.81 \pm 3.14$ & $13.43 \pm 3.46$ \\
SA + AL + EtOH (VIII) & $80.00 \pm 9.73^{\mathrm{a}, \mathrm{b}}$ & $45.40 \pm 2.82^{\mathrm{a}, \mathrm{b}, \mathrm{c}}$ & $88.25 \pm 3.79$ & $13.82 \pm 2.84$ \\
\hline
\end{tabular}

Values are expressed as means $\pm \mathrm{SD}$, a Mean difference is significant $(P<0.05)$ when compared with group $\mathrm{l}$, ${ }^{\mathrm{b}}$ Mean difference is significant $(P<0.05)$ when compared with group II, 'Mean difference is significant $(P<0.05)$ when compared with group III, $\mathrm{SA}=$ Sodium arsenite, EtOH $=\mathrm{Ethanol}, \mathrm{AL}=A$ framomum longiscapum

recombination and joining of single- and double-stranded DNA breaks. ${ }^{[32]}$

Excessive EtOH consumption can result in oxidative stress via mechanisms associated with $\mathrm{EtOH}$ metabolism that generate reactive oxygen species (ROS). ROS produced by cellular metabolic activity, and the alcohol-inducible enzyme (cytochrome P450 2E1) involved in $\mathrm{EtOH}$ metabolism, and activated hepatic macrophages (Kupffer cells) via EtOH-mediated endotoxemia can deplete cellular antioxidant defence capacity ${ }^{[15]}$ resulting in oxidative stress. The available evidence indicates that oxidative stress may result in DNA damage ${ }^{[33]}$ lipid peroxidation ${ }^{[34]}$ and promote hepatocyte death. Moreover, oxidative mechanisms can contribute to liver fibrosis, by triggering the release of pro-fibrotic cytokines and collagen gene expression in hepatic stellate cells. ${ }^{[35]}$

The application of plants products as drugs is as important to humans as their dietary source of nutrients. ${ }^{[36]}$ Humans have exploited plants for medicinal use, almost as long as they have cultivated them for food, using all part of plants in the art of healing diseases and enhancing health, within their immediate environment. ${ }^{[3]]}$ Natural products from higher plants have indeed offered humanity, clinically useful drugs, such as reserpine, vincristine, physostigmine, quinine, d-tubocurarine, ginseng, and artemisinin. ${ }^{[38]}$ Nigerian flora has contributed immensely to the health care of its populace from antiquity to cure ailments. ${ }^{[38-40]}$ However, little is known about the pharmacological efficacy of most herbal plants in use till date ${ }^{[41]}$ and their spectrum of activity.

This study examines the protective effect of $A L$ to Wister albino rats co-exposure to $\mathrm{SA}$ and $\mathrm{EtOH}$. Results from phytochemical studies [Table 1] show that the plant extract contains flavonoids, alkaloids, cardenolides, and saponins with concomitant absence of anthraquinone and tannins. The presence of these biologically active phytochemical — although assessed qualitatively —indicates that the extract of $A L$ may exhibit anti-oxidative properties. Mechanistically, AL may act as an antioxidant to mitigate the deleterious effect of free radicals generated from EtOH metabolism and Kupffer cells via endotoxemia as well as SA-mediated toxicity. The observed increase in body weight of group IV rats fed $A L$ only could be due to the androgenic properties of the plant since androgens possess anabolic activity ${ }^{[36]} \mathrm{EtOH}$ treatment alone also increased body and liver weight, this may be as a result of an increase in DNA synthesis we have earlier demonstrated that EtOH $(3 \% \mathrm{w} / \mathrm{v})$ promotes hepatic DNA synthesis (unpublished data). This increase is observed in all groups where $\mathrm{EtOH}$ is present with regard to liver weight gained compared 
with the control. These observed increases may in part be attributed to $\mathrm{EtOH}$ implication in the onset of fatty liver with enhanced cholesterol biosynthesis ${ }^{[42]}$ and oxidative mechanisms related to hepatic fibrosis with the release of pro-fibrotic cytokines and collagen gene expression in stellate cells. ${ }^{[3]}$

Co-administration of SA, AL, and EtOH (group VIII) decreased final body weight and liver weight significantly $(P<0.05)$ compared with control. The decrease in body and liver weight of group VIII rats may be attributed to the synergy of $A L, \mathrm{EtOH}$, and $\mathrm{SA}$ co-treatment. Liver weight of rats treated with SA alone [Table 2] decreases significantly $(P<0.05)$ compared with control confirming its potential hepatotoxicity. However, there was no significant $(P>0.05)$ increases in liver weight of the SA and EtOH treated group compared with the control group. A significant $(P<0.05)$ decrease in liver weight was observed in the $A L$-treated group when compared with groups I, II, III, V, and VI. Since little is known of the efficacy of AL, the decreases in liver weight may be related to the duration of exposure to $A L$. Consequently, its phytochemical antioxidative characteristics could have been altered and tend to become pro-oxidants. There was a significant $(P<0.05)$ decrease in relative liver weight across all the groups when compared with the control. Similarly, the relative liver weight in the $A L$-treated group decreases significantly $(P<0.05)$ compared with SA and EtOH treated groups.

The results of this study clearly demonstrate that SA, SA, and $\mathrm{EtOH}$ treatment significantly $(P<0.05)$ induced the formation of micronuclei in the polychromatic erythrocytes (mPCEs) of the rat bone marrow cells [Table 3]. These observations are consistent with earlier observations in our laboratory and those of others on the clastogenic potentials of SA in the bone marrow. ${ }^{[7,43]}$ In this particular investigation, the induction of $\mathrm{mPCE}$ by $\mathrm{SA}$ and $\mathrm{EtOH}$ was increased significantly $(P<0.05)$ more than four-fold when compared with the mPCEs induced in the bone marrow of the control group. Arsenite metabolism generates free radicals that can attack DNA leading to chromosomal breakage. In addition to acetaldehyde formation and other by-products of EtOH metabolism which can form DNA adducts that may increase DNA instability and enhance arsenite clastogenicity. Furthermore, SA and EtOH may have acted in synergy in mPCEs formation. However, from Table 3 , there was a significant $(P<0.05)$ decrease in mPCEs induction in the bone marrow in SA, EtOH, and $A L$-treated rats. More than a twofold decrease was observed when compared with groups II and III. This can be attributed to $A L$ antioxidant activities that help in scavenging ROS generated from EtOH and arsenite metabolism. Interestingly, there was also a significant $(P<0.05)$ increase in mPCEs induction in $A L$-treated rats compared with control, but there is no significant $(P<0.05)$ difference between control and EtOH-treated rats. The increase in mPCEs induction in $A L$-treated rats cannot be explained in the light of its anti-oxidative potentials. The AL extract may contain other uncharacterised components or its anti-oxidative characteristics could have been altered and to pro-oxidants with the possibility of having genotoxic effects.

Assessment of the serum activities of hepatic transaminases $(\gamma-G T, A L T$, and AST) show that SA alone, SA and EtOH increase serum activity of transaminases. SA and simultaneous administration of EtOH significantly $(P<$ $0.05)$ increased hepatic $\gamma$-GT activity in serum by about two- and threefold compared with the control [Table 4], this is inductive of hepatotoxicity and oxidative peroxidation in the hepatocyte cell membrane. Increased $\gamma$-GT activity in serum has been associated with hepatotoxicity, ${ }^{[44]}$ chromosomal aberrations, ${ }^{[45]}$ and oxidative stress in cells. ${ }^{[46]}$ In the group treated with $\mathrm{SA}, \mathrm{EtOH}$ and $A L$, the level of $\gamma$-GT activity decreased significantly $(P<0.05)$ when compared with SA alone, SA and EtOH-treated rats. This reduction may be due to the presence of bioactive phytochemicals in the $A L$ extract scavenging ROS and thereby reducing hepatocyte lipid peroxidation ${ }^{[4]}$ and reducing the damage $\mathrm{SA}$ and $\mathrm{EtOH}$ co-treatment would have induced. SA, SA and EtOH increased serum activity of hepatic transaminases (ALT and AST) [Table 4] significantly $(P<0.05)$ compared with control. However, ALT and AST activity decreased significantly $(P<0.05)$ in serum of the SA and EtOH treated group as well as $A L$-treated rats. The induction of ALT and AST activity following SA has been documented. ${ }^{[48]}$ It is important to note that these enzymes are mainly intracellular implying that any observed increase in serum is as a result of damage to hepatocyte leading their release into extracellular space resulting in increased plasma activities.

Sperm quality as an index of reproductive toxicity [Table 5] showed that $A L$ treatment caused a significant $(P<0.05)$ decrease in both sperm counts and motility compared with the control group. This is in accordance with the fact that the use of androgens containing compounds could negatively influence male rat fertility. ${ }^{[49]}$ Further decrease in sperm motility was also observed in rats treated with SA, EtOH, and AL. However, sperm viability in all treatment groups showed no significant $(P>0.05)$ effect, implying that $A L$ species could also influence male rat fertility positively. ${ }^{[49]}$ There was no significant increase in the morphological abnormality in the semen in all groups above what appears normal in this study, although $A L$ treatment tends to increase total abnormality alone and in the presence of SA and EtOH co-treatment. 


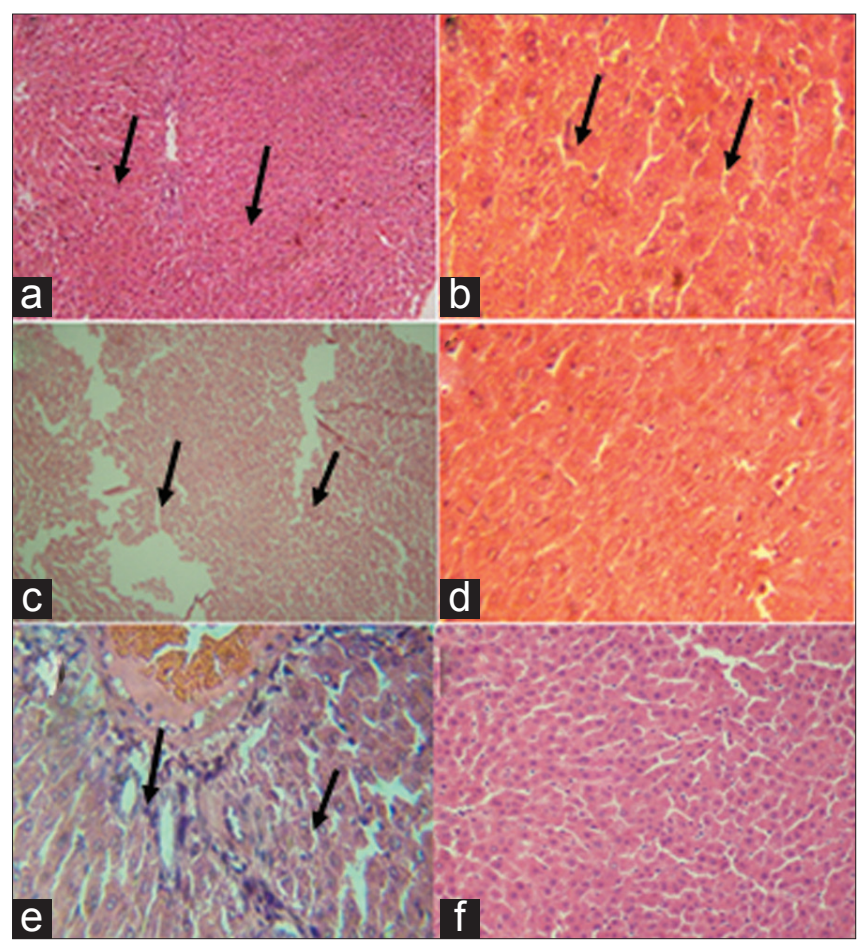

Figure 1: Photomicrograph of the liver sections at different magnifications, (a) Control rat: diffuse periportal vacuolar degeneration of hepatocytes with very mild cellular infiltration by mononuclear cells, (b) Sodium arsenite treated rat: there are multiple areas of extensive vacuolar degeneration of hepatocytes, (c) Sodium arsenite and ethanol treated rat: there is severe hepatic degeneration and necrosis (diffuse), (d) Aqueous extract of Aframomum longiscapum seed treated rat: no visible lesion seen, (e) Sodium arsenite $+\mathrm{EtOH}+$ aqueous extract of Aframomum longiscapum seed treated rat: mild hepatic degeneration, mild congestion of the portal vessels and mild mononuclear cellular infiltration, (f) EtOH alone. plates b, $d$ and e are $(\times 400)$ and $a, c$ and $f$ are $(\times 100)$ magnification

The limited histopathological examinations [Figure 1] show very mild cellular infiltration by mononuclear cells in the control group. Severe hepatic degeneration and necrosis was also observed in SA alone, SA and EtOH treated groups. No visible lesion was observed in the group treated with $A L$. However, mild hepatic degeneration and congestion of the portal vessels was observed in $A L, \mathrm{SA}$ and $\mathrm{EtOH}$ treated groups.

\section{CONCLUSION}

Taken together, our findings indicate that the aqueous extract of $A L$ may have hepatoprotective effects, ameliorate the hepatotoxic effects of SA and EtOH. The extract of $A L$ exhibited anticlastogenic properties by reducing $\mathrm{SA}$-induced micronuclei formation in polychromatic erythrocytes in the bone marrow. In terms of reproductive functions, $A L$ has a positive and negative effect on male rat fertility by enhancing semen morphology and decreasing sperm count, motility and viability, respectively. The aqueous extract of $A L$ has shown potential of mitigating the effect of arsenicals clastogenicity implicated in chemical-induced carcinogenesis.

\section{REFERENCES}

1. International Agency for Research on Cancer (IARC). Some Inorganic and Organometallic compounds: Monographs on the Evaluation of Carcinogenic Risk of chemicals to humans. Vol. 2. France: Lyon; 1973.

2. Yoshida T, Yamauchi H, Sun G. Chronic health effects in people exposed to arsenic via the drinking water: Dose-response relationships in review. Toxicol Appl Pharmacol 2004;198:243-52.

3. Chiou HY, Hsueh YM, Liaw KF, Horng SF, Chiang MH, Pu YS, et al. Incidence of internal Cancer and ingested inorganic arsenic: A seven-year follow-up study in Taiwan. Cancer Res 1995;55:1296-300.

4. Smith A, Goycolea M, Haque R, Biggs ML. Marked increase in bladder and Lung cancer mortality in a region of Northern Chile due to arsenic in drinking water. Am J Epidemiol 1998;147:660-9.

5. Tsuda T, Babazono A, Yamamoto E, Kurumatini N, Mino Y, Ogawa $\mathrm{T}$, et al. Ingested arsenic and internal cancer: A historical cohort study followed for 33 years. Am J Epidemiol 1995;141:198-209.

6. Odunola OA, Kazeem AA. Interaction and enhancement of the toxic effects of sodium arsenite and lead acetate in wistar rats. Afr J Biomed Res 2007;10:59-65.

7. Sharma A, Sharma MK, Kumar M. Modulatory role of Emblica officinalis fruit extract against arsenic induced oxidative stress in Swiss albino mice. Chem Biol Interact 2009;180:20-30.

8. Roy S, Roy M, Pandey PK, Tiwari SP. Effects of tissue trace minerals status and histopathological changes in chronic arsenicosis in goats. Vet World 2009;2:8-9.

9. Vutukuru SS, Prabhath NA, Raghavender M, Yerramilli A. Effect of arsenic and chromium on the serum amino-transferases activity in Indian major carp, Labeo rohita. Int J Environ Res Public Health 2007;4:224-7.

10. Das AK, Sahu R, Dua TK, Bag S, Gangopadhyay M, Sinha MK, et al. Arsenic -induced myocardial injury: Protective role of Corchorus olitorius leaves. Food Chem Toxicol 2010;48:1210-7.

11. Sinha D, Roy M, Siddiqi M, Bhattacharya RK. Arsenic-induced micronuclei formation in mammalian cells and its counteraction by tea. J Environ Pathol Toxicol Oncol 2005;24:45-56.

12. Lahon K, Das S. Hepatoprotective activity of Ocimum sanctum alcoholic leaf extract against paracetamol-induced liver damage in Albino rats. Pharmacognosy Res 2011;3:13-8.

13. El-Serag HB. Epidemiology of hepatocellular carcinoma. Clin Liver Dis 2001;5:87-107.

14. Longnecker MP. Alcohol consumption and risk of cancer in humans: An overview. Alcohol 1995;12:87-96.

15. Dey A, Cederbaum Al. Alcohol and oxidative liver injury. Hepatology 2006;43:S63-74.

16. Umukoro S, Ashorobi BR. Further pharmacological studies on aqueous seed extract of Aframomum melegueta in rats. J Ethnopharmacol 2007;115:489-93.

17. Fasoyiro SB, Adegoke, GO. Phytochemical characterization and the antimicrobial property of Aframomum danielli extract. Afr J Agric Res 2007;2:76-9.

18. Preston RJ, Dean BJ, Galloway S, Hoden H, McFee AF, Shelby M. Mammalian in vivo cytogenetic assays: Analysis of chromosome aberrations in bone marrow cells. Mutat Res 1987;189:157-65.

19. Harbourne JB. Phytochemical Methods: A Guide to Modern 
Technique of plants Analysis. London: Chapman and Hall; 1983. p. 94-103.

20. Heddle JA, Salamone MF. The micronucleus assay 1, in vivo. In: Stich HF, San RH, editors. Short Term Tests for Chemical carcinogens. Berlin: Springer Verlag; 1984. p. 243-9.

21. Szasz G. A kinetic photometric method for serum gamma glutamyl transferase. Clin Chem 1969;124:124-36.

22. Reitman S, Frankel S. A colorimetric method for the determination of serum glutamic oxaloacetic and glutamic pyruvic transaminases. Am J Clin Pathol. 1957;28:56-63.

23. Longnecker MP, Daniels JL. Environmental contaminants as etiologic factors for diabetes. Environ Health Perspect 2001;109:871-6.

24. Tseng WP. Effects and dose-response relationships of skin cancer and blackfoot disease with arsenic. Environ Health Perspect 1977;19:109-19.

25. Klaassen CD. Heavy metals and heavy metal antagonists. In The Pharmaceutical Basis of Therapeutics. New York: Pergamen Press; 1990. p. 1602-5.

26. Waalkes MP, Ward JM, Liu J, Diwan BA. Transplacental carcinogenicity of Inorganic arsenic in the drinking water: Induction of hepatic, ovarian, pulmonary and adrenal tumors in mice. Toxicol Appl Pharmacol 2003;186:7-17.

27. Prasad SJ, Pandey K. Impaired spermatogenesis in arsenic treated freshwater fish, Colisa fasciatus (BI. and Sch.). Toxicol Lett 1984;21:191-5.

28. Guha Majumdar DN. Effect of chronic intake of arseniccontaminated water on liver. Toxicol Appl Pharmacol 2005;206:169-75.

29. Chattopadhyay S, Ghosh S, Debnath J, Ghosh D. Protection of sodium arsenite induced ovarian toxicity by co-administration of L-Ascorbate (Vitamin C) in mature Wistar strain rat. Arch Environ Contam Toxicol 2001;41:83-9.

30. Sunderman FW. Recent advances in metal carcinogenesis. Ann Clin Lab Sci 1984;14:93-122.

31. Li JH, Rossman TG. Inhibition of DNA ligase activity by arsenite: A possible mechanism of its co-mutagenesis. Mol Toxicol 1989;2:1-9.

32. Lasko DD, Tomkinson AE, Lindahl T. Eukaryotic DNA ligases. Mutat Res 1990;236:277-87.

33. Halliwell B, Aruoma OI. DNA damage by oxygen-derived species. FEBS Lett 1991;281:9-19.

34. Shah H, Hartman SP, Weinhouse S. Formation of carbonyl chloride in carbon tetrachloride metabolism by rat liver in vitro. Cancer Res 1979;39:3942-7.

35. Albano E. Alcohol, oxidative stress and free radical damage. Proc Nutr Soc 2006;65:278-90.
36. Muhammad S, Amusa NA. The important food crops and medicinal plants of north western Nigeria. Res J Agric Biol Sci 2005;1:254-60.

37. Cragg GM, Newman DJ. Natural products drug discovery in the next millennium. Pharm Biol 2001;39:8-17.

38. Soejarto DD. Biodiversity prospecting and benefit-sharing: Perspectives from the field. J Ethnopharmacol 1996;51:1-15.

39. Abila B, Richens A, Davies JA. Anticonvulsant effects of extracts of the West African black pepper, Piper genineese. J Ethnopharmacol 1979;39:113-7.

40. Gill LS. Ethnomedical uses of plants in Nigeria. Benin City: UNIBEN Press; 1992. p. 12-5.

41. Akah PA, Nwambie Al. Evaluation of Nigerian traditional medicine: Plants used for rheumatic (inflammatory) disorder. J Ethnopharmacol 1994;42:179-82.

42. Fernández-Checa JC. Alcohol-induced liver disease: When fat and oxidative stress meets. Ann Hepatol 2003;2:69-75.

43. Odunola OA. Comparative effects of some local food condiments on sodium arsenite induced clastogenicity. Afr J Med Med Sci 2003;32:75-80

44. Dinari G, Cohen MI, McNamara H, Kochen JA. Effect of lead exposure on the activity of some hepatic enzymes in rat. Pediatr Res 1979;5:644-6.

45. Karmaker R, Banerjee A, Datta S, Chatterjee M. Influence of cadmium intoxication on hepatic lipid peroxidation, glutathione level and glutathione S-transferase and gamma-glutamyl transpeptidase activities: Correlation with chromosome aberration in bone marrow cells. J Environ Pathol Toxicol Oncol 1999;18:277-87.

46. Lee $\mathrm{DH}$, Blomhoff R, Jacobs DR. Is serum gamma glutamyl transferase a maker of oxidative stress? Free Radic Res 2004;38:535-9.

47. Wiseman $H$. Dietary influences on membrane function: Importance in protection against oxidative damage and disease. J Nutr Biochem 1996;7:2-15.

48. Mallick P, Mallick JC, Guha B, Khuda-Bukhsh AP. Ameliorating effect of micodoses of potentized homeopathic drug, Arsenicum album, on arsenic-induced toxicity in mice. BMC Complement Altern Med 2003;22:3-7.

49. Mbongue FG, Kamtchouing P, Essame OJ, Yewah PM, Dimo T, Lontsi D. Effect of the aqueous extract of dry fruits of Piper guineense on the reproductive function of adult male rats. Indian J Pharm 2005;37:30-2.

Cite this article as: Owumi SE, Odunola OA, Aliyu M. Co-administration of sodium arsenite and ethanol: Protection by aqueous extract of Aframomum longiscapum seeds. Phcog Res 2012;4:154-60.

Source of Support: Nil, Conflict of Interest: None declared. 